\title{
Valuing nurse and midwifery unit managers' voices: a qualitative approach
}

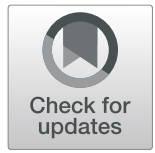

Cate Nagle ${ }^{1,2^{*}}$, Olumuyiwa Omonaiye ${ }^{1}$ and Paul N Bennett ${ }^{3}$

\begin{abstract}
Background: Nurse and Midwifery Unit Managers (NMUMs) play pivotal roles in quality patient care, nurse and midwife satisfaction and retention. NMUMs are expected to be both leaders and managers simultaneously, which may create role tension. This study aimed to explore the understanding and experience of NMUMs regarding their role; to explore what barriers and facilitators NMUMs identified to achieving the goals of their clinical area; and to explore NMUMs' career plans.

Methods: Set in Victoria, Australia, this study was guided by naturalistic inquiry using a qualitative descriptive approach. Thematic analysis was used to inductively develop core themes, which facilitated the motivations, experience and meanings underlying the data to be elaborated.
\end{abstract}

Results: In all, 39 interviews were conducted with NMUMs across four hospitals. Two overarching themes were identified from the data; system challenges and influences on people and each theme had three sub-themes. In relation to system challenges, participants spoke about the structural challenges that they encountered such as financial stressors and physical infrastructure that made their work difficult. Participants felt they were unprepared for the NMUM role and had limited support in the preparation for the role. Participants also related their frustration of not being included in important decision-making processes within the hospital. Regarding their career plans, most did not envisage a career beyond that of a NMUM.

Conclusions: This study of contemporary NMUMs uncovered a continued lack of investment in the orientation, professional development and support of this critical leadership and management role. There is an urgent need for targeted interventions to support and develop capabilities of NMUMs to meet the current and evolving demands of their role.

Keywords: Nurse unit manager, Midwifery unit manager, Leadership, Heath care management, Patient safety

\section{Background}

Nurse and Midwifery Unit Managers (NMUMs) play pivotal roles in quality patient care, nurse and midwife satisfaction and retention [1]. The NMUMs' role includes change agent; coach; mentor; finance and human resource manager; clinical expert; educator; quality

\footnotetext{
* Correspondence: cate.nagle@jcu.edu.au

'Centre for Nursing and Midwifery Research, James Cook University, 1 James Cook Drive, Queensland 4814 Townsville, Australia

${ }^{2}$ Townsville Hospital and Health Service, Townsville Institute of Health Research and Innovation, Townsville, Queensland, Australia

Full list of author information is available at the end of the article
}

manager and patient advocate [2,3]. Nurses who appraise their practice environments positively, are less likely to report burnout and leave their position, compared to nurses with a negative appraisal of their practice environments [4, 5]. Furthermore, higher level nurse-reported quality of care, has been associated with work environments where nurses have reported a feeling of being empowered to carry out their work [6].

Irrespective of the position title or experience that nurses and midwives may possess, leadership is a role that all are expected to fulfil $[7,8]$. A leader inspires and influences others to act while at the same time directing

C The Author(s). 2021 Open Access This article is licensed under a Creative Commons Attribution 4.0 International License, which permits use, sharing, adaptation, distribution and reproduction in any medium or format, as long as you give appropriate credit to the original author(s) and the source, provide a link to the Creative Commons licence, and indicate if changes were made. The images or other third party material in this article are included in the article's Creative Commons licence, unless indicated otherwise in a credit line to the material. If material is not included in the article's Creative Commons licence and your intended use is not permitted by statutory regulation or exceeds the permitted use, you will need to obtain permission directly from the copyright holder. To view a copy of this licence, visit http://creativecommons.org/licenses/by/4.0/. The Creative Commons Public Domain Dedication waiver (http://creativecommons.org/publicdomain/zero/1.0/) applies to the data made available in this article, unless otherwise stated in a credit line to the data. 
the way that others act. Thus, leadership requires qualities that extend beyond management skills [9]. Conversely, a manager seeks to meet goals while following organisation rules [9].

NMUMs are expected to carry the responsibilities and exhibit the functions of a leader and a manager simultaneously $[10,11]$. This involves NMUMs developing a vision and operationalising nurses and midwives towards this vision. However, being both a leader and a manager can create tensions in the NMUMs' role [11]. Leadership has been viewed as one of the many functions of a manager, despite the fact that others might view management as a role of leadership [11]. Nevertheless, there is the contention that both management and leadership may not come together in one individual. This is because of the diverse factors in a workplace environment that make it challenging for one individual to be true to both, and that attempting to do so can result in internal conflict [12]. Hence, because of the diverse motivators and objectives in a dynamic workplace environment, there is a need for leadership training and organisational support to enhance NMUMs' performance.

In 2016, Western Health, Victoria, Australia, initiated a review of the Unit Manager role including interviews with NMUMs to inform an organisation wide professional development of this staff group. Western Health includes several hospitals and a wide range of community based services. These services are provided mainly for the western region of Melbourne, which has a catchment population of about 800,000 people [13]. One of several information sources to inform this initiative was the NMUMs themselves. It was considered vital to the success of the overall program that NMUMs were able to describe their experiences of management and leadership within their roles and relate areas of strength and areas requiring development, for the program to be relevant and responsive. The objectives of this study were: to explore the understanding and experience of NMUMs regarding their role; to explore what barriers and facilitators NMUMs identified to achieving the goals of their clinical area; and to explore NMUMs' career plans.

\section{Methods}

\section{Research design}

The study was guided by naturalistic inquiry using a qualitative descriptive approach [14]. There are three main tenets that underpin naturalistic inquiry: the phenomenon should be studied in context; the object of interest should be examined without reference to a priori theoretical frameworks and the researchers' preconceived assumptions should be explicit; and the research is interpretive [14]. In this study, naturalistic inquiry provided an ideal method to explore NMUMs' leadership perspectives. In order to ensure trustworthiness of qualitative data the four criteria proposed by Guba (1981) were applied in this study [15]. These four criteria are credibility, transferability, dependability and confirmability.

\section{Setting and participants}

This study was conducted in four hospitals: Sunshine Hospital; Footscray Hospital; Sunbury Day Hospital; and Williamstown Hospital, all under the management of Western Health, Victoria, Australia. Selection criteria included all NMUMs employed during the data collection period.

Sunshine Hospital is an acute and subacute teaching hospital with approximately 600 beds. The hospital provides: elective and emergency services with a range of inpatient and outpatient services including intensive care and coronary care; acute medical and surgical services; sub-specialty medicine and surgical services; rehabilitation; aged care and palliative care services; and women's and children's services. Footscray Hospital is an acute and subacute teaching hospital with approximately 300 beds and provides elective and emergency services, with a range of inpatient and outpatient services including: acute general medical and surgical; intensive and coronary care; sub-specialty medicine; surgical services; rehabilitation and aged care. Williamstown Hospital is a 90-bed facility providing emergency services, surgical services, rehabilitation and geriatric evaluation and management services, renal dialysis services and community rehabilitation and transition care services. At the Sunbury Day Hospital the services provided include day medical, day surgical, day chemotherapy and haemodialysis treatment, and several specialist clinics.

\section{Sampling approach and recruitment of participants}

A population based sampling [16] approach was used and all NMUMs were invited to participate in a face-toface, semi-structured interview. This sampling approach was selected to ensure that all NMUMs had the opportunity to inform the professional development intervention and engaged early in the process. A distribution list of the names and contact details of NMUMs was provided to staff independent of the research team. NMUMs were sent an email describing the study with an invitation to participate in an interview from a person independent of line management. The initial email contact was followed by a phone call from a research team member to provide clarification and respond to any questions. An interview was scheduled at a mutually convenient time for those interested in participating. Participants received a hard copy of the plain language statement and consent form before providing written consent. 


\section{Data collection}

Interviews were scheduled at a site convenient to the NMUM and in a private, neutral environment. A semistructured interview schedule was used to guide discussion. During the interviews, participants were asked open-ended questions about their role and perspectives of leadership (Fig. 1). In addition, details were sought about their understanding of the barriers and facilitators to the NMUM's role and their career plans. Data were collected using individual interviews rather than focus groups with the rationale that some individual participants may be more comfortable to share their insights in a one to one discussion. All interviews were digitally recorded with consent of the NMUMs and professionally transcribed. Transcripts were coded numerically 001039.

\section{Data analysis}

An inductive inference method underpinned the methodological approach that guided this study. This approach allowed new knowledge to be generated based on data that was collected [17]. Data collected from the transcripts was systematically analysed using a thematic analysis framework. Thematic analysis is also used to systematically develop core themes based on an inductive approach which allows the motivations, experience and meanings underlying the data to be elaborated upon in a straightforward manner [18]. Thematic analysis of the transcribed data was conducted using Braun and Clarke's (2006) Framework. Initially, familiarisation of the data occurred by reading through the verbatim transcribed files. Initial themes were identified, and synthesis of collated themes was undertaken independently by members of the research team $(\mathrm{CN} \&$ $\mathrm{OO})$. Identified themes were reviewed and refined by the research team.

\section{Ethical considerations}

Organisational ethics approval for this study was granted by Western Health Low Risk Ethics Panel (LNR/ $15 / \mathrm{WH} / 123)$. The study was conducted in accordance with the principles of the Helsinki Declaration. Written informed consent was obtained from all participants before the start of each interview. No identifying details were collected.

\section{Results}

A total of 39 of the health services' 51 NMUMs participated in interviews conducted between November 2015 and April 2016; NMUMs from all four sites of the health service participated. Many of the NMUMs had been employees at Western Health for many years and few had previously held senior roles in other health services. Almost all participants were female $(n=37,94.9 \%)$. The median years as an NMUM was $4(\mathrm{IQR}=5.5)$. However, of note ten NMUM had been in the position for less than one year. The median duration of interviews was $48.5 \mathrm{~min}$, ranging from minimum of $37 \mathrm{~min}$ to a maximum of $66 \mathrm{~min}$.

Two overarching themes were identified from the data; system challenges and influences on people (Table 1) and each theme had three sub-themes.

\section{System Challenges}

The NMUMs related that their managerial position had increased in scope over time with wider responsibilities for patient care and management, leadership of staff, administration and management of resources. In a bid to operationalise these multidimensional roles and functions, NMUMs encountered diverse system challenges.

Three sub-themes emerged that demonstrated impediments that NMUMs faced in the day to day running of their units and made it difficult for them to achieve their

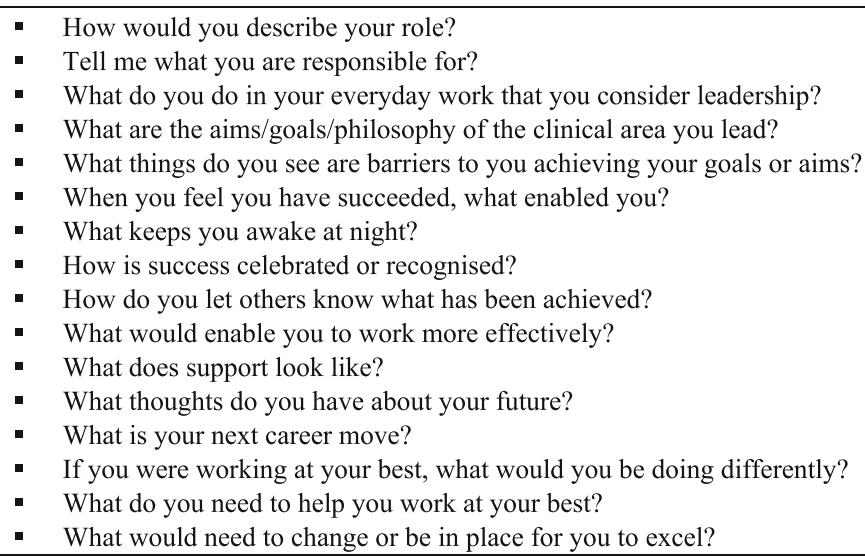

Fig. 1 Semi structured interview Guide 
Table 1 Major themes and sub-themes relating to the perspectives of Nurse Midwife Unit Mangers (NMUMs) role

\begin{tabular}{|c|c|c|}
\hline $\begin{array}{l}\text { Major } \\
\text { themes }\end{array}$ & Sub-themes & Sub Sub-themes \\
\hline \multicolumn{3}{|c|}{$\begin{array}{l}\text { Systems } \\
\text { Challenges }\end{array}$} \\
\hline & Structural challenges & $\begin{array}{l}\text { Institutional deficits-financial and physical infrastructureln adequate support from other systems/ } \\
\text { structures/departments.Challenges of working with hospital managementlnadequate support from } \\
\text { systems and department within the hospital management.Feelings of not being supported by su- } \\
\text { periors/hospital management.Not included in decision making within the organisation.Adherence } \\
\text { to organisational policies and procedure }\end{array}$ \\
\hline & Role preparation & $\begin{array}{l}\text { Unprepared for the NMUM roleStruggling with self confidenceProfessional development for } \\
\text { NMUMCareer plans }\end{array}$ \\
\hline & $\begin{array}{l}\text { Managerial and administrative } \\
\text { functions of role }\end{array}$ & $\begin{array}{l}\text { Administrative responsibilities taking time from clinical timeStaffing and skill mix issues and dealing } \\
\text { with difficult staff.Delegation of duties }\end{array}$ \\
\hline \multicolumn{3}{|c|}{$\begin{array}{l}\text { Influences of } \\
\text { people }\end{array}$} \\
\hline & Leadership & $\begin{array}{l}\text { Being accessibleLeading by example and taking responsibilityBuilding a functional teamTreating } \\
\text { everyone with fairness, respect and equally.Succession plans/people developer }\end{array}$ \\
\hline & Putting the patient first & Clinical responsibilities main feature of roleMultidisciplinary interactionMaintaining quality \\
\hline & Personal sacrifices & $\begin{array}{l}\text { Long hours of workDemand of work affecting family/personal lifeShouldering some of the persona } \\
\text { burdens of subordinates }\end{array}$ \\
\hline
\end{tabular}

goals as a NMUM (Table 1). These three sub-themes are: Structural challenges, role preparation, managerial and administrative functions of role.

\section{Structural challenges}

Participants talked about the structural challenges that they encountered in the form of institutional deficits, financial and physical infrastructure that made their work onerous. As one participant remarked:

It makes it a very difficult task and [a] very time -consuming task when all I want is a medication fridge. [023].

Participants commented on the indignation they felt seeing patients in undignified conditions because of infrastructural inadequacies in the hospital:

Having patients paraded through the cafeteria area on their beds while they're going from one ward to another or going to have a scan is the most awful thing to see. [009]

Participants echoed the challenges of working with hospital management and the associated stress that comes with this working relationship:

The other thing I find when I did have conversation with my manager is sometimes if I need something I have to go through 10, 15 questions so why do I need - explain, provide rationale for that. So last time I said to him, well, if you really don't trust my judgment, I don't think I should be in the position [009].

Inadequate support from other systems and departments within the hospital was also uppermost in the minds of most of the participants. As one participant remarked:

\section{...I struggle with my operations manager because < identifier removed > doesn't get it. [014]}

Participants wanted to have some form of validation of the work they were doing and had hoped that their managers would be there for them to support their leadership efforts. Some participants expressed the feeling of not been supported by managers and/or hospital management.

The other thing that I've found is ... the Director of Nursing, I used to see them at least once a week. I've been here eight months; I haven't seen the Director of Nursing on my ward as yet. [009]

However, some participants expressed that they felt supported by their service group director. As a participant remarked:

...my ops manager is very good in actually guiding me - this is my first year actually with ... and I've learned so much from him. [010]

Participants also talked about their frustration of not being included in important decision-making processes within the hospital: 
I find that frustrating because there isn't that overall understanding of the workforce and it seems to me that the NEAT targets drive everything. [014]

NEAT refers to National Emergency Access Targets. These are Australian federal government performance indicators for hospitals measuring the time from emergency presentation to discharge from the emergency department or to admission.

Despite the structural challenges that confronted the participants in their day to day running of their units, they were still focused on adhering to the policies and procedures of their organisations:

Policies, adherence to policy, adherence to procedures, adherence to guidelines, adherence to the ... values... you need to be able to communicate to people as to why those things are important and expect them to carry out those roles. [012]

\section{Role Preparation}

Most participants felt they were unprepared for the NMUM role and had had limited support in their preparation for the role.

There's no orientation to a NUM role, you just sort of here's roster on, here's - you need to use recruit, you need to do this, you need to - there's no structure in how you learn these tools that you're supposed to use. There's no formal education in how you use these tools. [007]

In the few instances where there was orientation, participants were not satisfied with orientation process. As a result of lack of preparation and capacity building before taking on the role of NMUM position some participants struggled with self-confidence.

Many of the participants identified that professional development and mentorship would assist them in their NMUM role. As this participant explained:

I think if there's going to be more expectations of the Nurse Unit Managers, then there needs to be some more education ...Project management, change management, how to write a business case. [007]

Participants were asked about their career plans and most did not envisage a career beyond that of Unit Manager or they were unsure.

... it doesn't seem like there's a great future for me to go anywhere else or develop anymore or help develop anyone else. So it's very much now just being here and doing what I've been doing... [022].
Few participants identified an intent to undertake further study or a change of career.

Just working in public health, maybe being an epidemiologist or working in epidemiology or doing research. [028]

I've thought about maybe doing some more study at some point. ... Well probably just in the management side of - something that's relevant to my role at the moment. [026]

\section{Managerial and administrative functions of role}

Participants revealed that they were concerned that their administrative responsibilities were taking more time away from clinical time.

... I think I would be very sad if I would have to give up my clinical time, because I really enjoy my clinical time. But then I'm finding that my admin days two admin days is just not adequate for me to do everything that I need to do. [009]

Participants identified staffing and skill mix issues and dealing with difficult staff as critical managerial function that they had to confront in order to run their units successfully.

So obviously it's incredibly difficult to recruit staff. It's not just staff, it's ... trained staff......... The skill mix... high reliance and you know just for the senior staff on the unit, helping support new staff, making sure everyone is safe, making sure patients are safe, it's been a huge workload for everyone. [012]

To effectively run their units, few participants demonstrated the ability to delegate aspects of their NMUM role to their staff. One NMUM who did delegate responsibilities related:

It is important to set up portfolios. So I have an infection control portfolio... I have the rostering portfolio. We have the ordering portfolio. Very important stuff... There's an admission portfolio.... So those people all have responsibilities in their areas.... I find if you have those portfolios and those structures really early and you get the right people in them, your place runs really well. So I've been fairly successful as a manager [013].

\section{Influences on people}

The second overarching theme was influences on people. Participants described their NMUM role in terms of 
investing and supporting their staff, leading and influencing their teams and being accountable and responsible for the care provided. In this theme there were three sub-themes: Leadership; putting patients first; and personal sacrifices.

\section{Leadership}

In describing how they provided leadership in their everyday practice several key elements were described by the participants. Being an accessible leader was stated as very important.

I've got an open-door policy. ... there are managers in the past who have not allowed the staff to talk to them. I tell them where I'm going. I'm off-floor today, I'll be - if you need, see me by 12. If it's urgent email me and I'll get back to you tonight after work. [013].

Another attribute that the participants described as an example of their leadership was leading by example and taking responsibility to influence the behaviour of staff.

I want to lead the team actually in a cohesive and a united team. So that's really my aim and that's why I still deliver quality care, standard of care and you know good teamwork and it's easy for everyone. [009]

For some participants, leadership was evidenced by building a functional team that can deliver effectively on team goals by the complementary use of skill sets.

Finding out where staff want to work, what they don't want to do. Trying to put people in and move them around to best suit the needs of the unit, the needs of the organisation and the staff's needs. [012]

The participants also identified their interactions with staff as a demonstration of their leadership. Treating others with respect and in an equitable and transparent manner were examples of leadership in their NMUM roles.

I make it very clear that whether you're the CEO or you're the cleaner, I speak exactly the same. I might change my vernacular, but I do not treat them any differently basically. So everyone is treated exactly the same... [013].

Participants demonstrated their leadership acumen by developing succession plans. This contrasted with the abrupt manner many participants experienced at the commencement of their role as NMUM. As this participant explained:

Also developing my staff, so also going through succession planning. At the moment I have one of my nurses acting up as an ANUM, so coaching her, showing her how to do things or things like that. [009]

\section{Putting patients first}

In describing their NMUM role, participants related a wide diversity of responsibilities. Participants described clinical responsibilities as a main feature of their role, particularly in terms of working with staff 'on the floor', to ensure that a high standard of care was provided. Participants demonstrated their mission of putting the patient first regardless of the constraining situation that they might be facing.

Again, I need to provide care to the patients, so I'm not going to compromise patients' care just because I have to explain at the end of the month - why did I spend more? [009]

So I say to my staff that they're - they come second to the patient. At the end of the day the patient is number one. Without them I don't have a job. So they're a very close second, but they're second. [013]

For some participants multidisciplinary interaction based on communication and co-operation with other team members was crucial to ensure that patients' interests were upheld.

I guess in my current role a lot of my responsibility is around, I guess, communicating and negotiating with other groups of people to make sure that the patient has a good journey through the system, really. [006]

Participants also saw patient safety as their number one priority. As this participant remarked:

My role is first and foremost to protect the patients' safety and to - my other part of my role is to provide leadership and direction to the unit... [014].

\section{Personal sacrifices}

Some participants described the NMUM role in terms of the personal sacrifices that they had to undertake to ensure the optimal functioning of their unit. For example, participants worked long hours as a routine to ensure positive outcomes for their units. As this participant explained:

I work longer hours, it's for me actually to finish my own work but because I want myself to be visible on the floor to make sure that they're all supported. I 
want myself to be involved in whatever they do because I always wanted them to come to me and feel free so that I know where they're at the level of understanding, the level of - their coping mechanism. [010].

Participants talked about how their family life was being affected because of the extra-commitment that they are putting into their job.

I guess I'll be honest, recently this year my partner said to me that I need to really take a long hard look at what I'm doing because I'm not home before $7 \mathrm{pm}$. I've got a three-year-old who is starting to ignore me because I'm not there. I'm gone sometimes before he wakes up. [012]

Despite the huge burden of responsibilities on the shoulders of the NMUMs, they were able to listen to and accommodate problems that their staff were facing in their personal lives. As this participant stated:

... when they've got depression or they're having family issues or divorces. They need to find someone they're very confident that I'm not going to tell anyone about their problems. I treat them exactly the same. [008]

\section{Discussion}

This study aimed to understand: the experience of the NMUMs' role; the barriers to, and facilitators of, achieving their unit's goals; and the NMUMs' career perspectives. The findings from this study showed that many NMUMs were nurses and midwives who were appointed to their positions without an orientation or the provision of a mentor. In addition to a lack of preparation for the role, some NMUMs experienced a lack of role clarity that led to low self-confidence and feeling ill-equipped to carry out the requirements of the position. Low selfconfidence on the part of the NMUMs may have cascading effects on the system [19] which may lead to reduced patient satisfaction and staff productivity $[1,19]$ as well as staff retention $[1,19]$. Our findings suggest a need to address the NMUM preparation as a priority to contribute to staff and patient satisfaction.

Our study further revealed that targeted professional development programs on subjects such as project management, change management and business case development can enhance the capacity of NMUM to deliver effectively on their multifaceted responsibilities. Consistent with our findings, previous studies have identified confusion among NMUMs concerning the boundaries and expectations of their role, worsened by inadequate professional development opportunities relating to leadership and management in Australia [6, 20, 21], New Zealand [22], Ireland [23] and South Africa [24].

The contemporary role of NMUMs requires managerial, leadership and clinical skills [25]. Our study revealed that NMUMs were worried that their administrative responsibilities were taking more time away from their clinical leadership responsibilities. This reported drift of NMUMs from one of their core responsibilities because of increased administrative workload has the potential to compromise patient safety unless there is a restructure of roles and responsibilities. In line with our finding, evidence shows that about $65 \%$ of a NMUM's role is largely related to general management activities such as staff management and budgeting, with only $16 \%$ of tasks being clinically related to patient care [25]. Therefore, it is not surprising that because of this shift in responsibilities, some have advocated that the position of the NMUM may be occupied by someone who is not a nurse [26]. This view has been espoused based on public management literature $[27,28]$ which alludes to the idea that any manager can manage any business [26, 27]. However, this view overlooks the everyday clinical realities that NMUMs face daily and the associated complex decisions they make relating to patient and staffing issues such as staff turnover, high part-time employment, skill mix of staff, high bed occupancy and unplanned admissions which can impact on patients' morbidity and mortality [29]. However, if the clinical time of NMUM continues to decrease as a result of increased administrative responsibilities, the voices advocating for nonnurses to occupy the position of unit managers may become louder and even become legitimate. A recent qualitative evaluation of an intervention to reduce the administrative burden of NMUMs in Australia via the introduction of a clerical Nurse Unit Manager Support Officer position, showed that administrative support for NMUMs improved the capacities of NMUMs to undertake clinical leadership and to be strategic leaders [30].

Of note in this study was the self-sacrifices of the NMUMs. NMUMs exemplified their personal sacrifices through long hours of work and shouldering some of the personal burdens of nurses and midwives. Our study revealed that these extra commitments to their positions by NMUMs was also affecting their family life in a negative way. This culture of self-sacrifice among NMUMs is historically embedded within the nursing profession and may lead to burnout, job dissatisfaction and presenteeism [31]. A self-sacrificing image of NMUMs may also discourage prospective recruits from taking up the role of NMUMs. Thus, the detrimental over-exertion and the lack of self-care within the ranks of NMUMs needs to be addressed to reduce retention challenges. Previous studies have linked personal factors such as burnout with intent to leave [32, 33]. Both theoretical and 
empirical works support the use of nurses' intention to leave as a proxy construct for actual turnover [34-36].

\section{Strengths and limitations}

A strength of the study is the richness of the data available for analysis and the rigour of the data collection and analysis processes. Credibility, confirmability, dependability, and transferability ensure the rigour of a study [37] and in this study credibility was demonstrated through reflexivity, maintaining an audit trail, and the use of detailed descriptions in interpreting the data. Methods used in this study to establish confirmability included reflexive journaling, and a clearly identified audit trail. The transparent audit trail detailed the rationale for decisions made throughout the research process to assist establish dependability. Transferability was promoted by the large sample size and the description of the context of the study. A limitation of this study is that while it involved NMUM from four hospitals, all were from one health service which may limit transferability of findings.

\section{Conclusions}

This study of contemporary NMUMs reveals that there continues to be a lack of investment in the orientation, professional development and support of this critical leadership and management role. Effective leadership is critical to the performance of a well-functioning hospital unit and to patient safety. Many NMUMs report feeling ill-equipped, unsure of the expectations of their role, and often overwhelmed with the demands of the position with minimal or no support from systems within the hospital. With an increasing trend to administrative and budgetary requirements within the NMUM role, the way forward is targeted interventions to support and develop capabilities of NMUMs or to introduce another model of management.

\section{Acknowledgements}

Organisational support for this study is acknowledged and we wish to thank the Directors of Nursing at Western Health for championing the study. We acknowledge the administrative support provided by Mel Moore and Michelle Scoble and their assistance with recruitment, scheduling of interviews and organising rooms. Most of all, we would like to thank all participants for their time and generosity in sharing their experiences of and thoughts on their role as a NMUM.

\section{Authors' contributions}

CN and PN proposed the research idea, CN and PN participated in data collection. $\mathrm{OO}$ and $\mathrm{CN}$ analysed the data. $\mathrm{OO}$ prepared Table 1; Figure 1. OO wrote the first draft of the manuscript. All authors critically reviewed subsequent drafts and approved the final manuscript.

\section{Funding}

Not applicable.

\section{Declarations}

Ethics approval and consent to participate

Organisational ethics approval for this study was granted by Western Health Low Risk Ethics Panel (LNR/15/WH/123). The study was conducted in accordance with the principles of the Helsinki Declaration. Written informed consent was obtained from all participants before the start of each interview. No identifying details were collected.

Consent for publication

Not Applicable.

\section{Competing interests}

The authors declare there are no financial and non-financial conflict of interests.

\section{Author details}

${ }^{1}$ Centre for Nursing and Midwifery Research, James Cook University, 1 James Cook Drive, Queensland 4814 Townsville, Australia. ${ }^{2}$ Townsville Hospital and Health Service, Townsville Institute of Health Research and Innovation, Townsville, Queensland, Australia. ${ }^{3}$ University of South Australia, Adelaide South Australia, Australia.

Received: 17 March 2021 Accepted: 18 August 2021

Published online: 06 September 2021

\section{References}

1. Ngabonzima A, Asingizwe D, Kouveliotis K. Influence of nurse and midwife managerial leadership styles on job satisfaction, intention to stay, and services provision in selected hospitals of Rwanda. BMC Nursing. 2020; 19(1): 35.

2. Hewko SJ, Brown P, Fraser KD, Wong CA, Cummings GG. Factors influencing nurse managers' intent to stay or leave: a quantitative analysis. J. Nurs. Manag. 2015; 23(8):1058-1066.

3. Warshawsky N, Rayens M, Stefaniak K, Rahman R. The effect of nurse manager turnover on patient fall and pressure ulcer rates. J. Nurs. Manag. 2013; 21(5):725-732.

4. Dyrbye LN, Shanafelt TD, Johnson PO, Johnson LA, Satele D, West CP. A cross-sectional study exploring the relationship between burnout, absenteeism, and job performance among American nurses. BMC Nursing. 2019; 18(1):57

5. Van Bogaert P, Clarke S, Wouters K, Franck E, Willems R, Mondelaers M. Impacts of unit-level nurse practice environment, workload and burnout on nurse-reported outcomes in psychiatric hospitals: A multilevel modelling approach. Int J Nurs Stud. 2013; 50(3):357-365.

6. Clarke E, Diers D, Kunisch J, Duffield C, Thoms D, Hawes SUE, Stasa H, Fry M. Strengthening the nursing and midwifery unit manager role: an interim programme evaluation. J. Nurs. Manag. 2012; 20(1):120-129.

7. Mc Carthy VIC, Murphy A, Savage E, Hegarty J, Coffey A, Leahy-Warren P, Horgan A, O'Connell R, Marsh L, Drennan J. Perceived importance and performance of clinical leadership in practice: A cross-sectional study of nurses and midwives of all grades. J. Nurs. Manag. 2019; 27(8):1738-1746.

8. Marshall ES: Transformational Leadership in Nursing: From Expert Clinician to Influential Leader, Second Edition edn. New York, NY: Springer; 2017.

9. What is leadership?Available at: [https://www.thebalancesmb.com/lea dership-definition-2948275]Accessed January 20: 2021

10. Rigolosi ELM: Management and Leadership in Nursing and Health Care: An Experiential Approach, Third Edition edn. New York: Springer Publishing Company; 2013

11. Marquis B, Huston C: Leadership Roles and management Functions in Nursing: Theory and Application, 8 edn. China: Wolters Kluwer; 2015.

12. Stanley D: Clinical Leadership. Innovation into action. South Yarra: Palgrave MacMillan: 2011.

13. Western Health:Our Community.Available at: [https://www.westernhealth. org.au/AboutUs/Pages/default.aspx]Accessed 12 Feb 2021

14. Bradshaw C, Atkinson S, Doody O. Employing a Qualitative Description Approach in Health Care Research. Glob. Qual. Nurs. Res. 2017; 4: 2333393617742282.

15. Guba EG. Criteria for assessing the trustworthiness of naturalistic inquiries. ERIC/ECTJ Annual Review Paper 1981; 29(2):75. 
16. Galloway A: Non-Probability Sampling. In: Encyclopedia of Social Measurement. edn. Edited by Kempf-Leonard K. New York: Elsevier; 2005: 859-864.

17. Hudson AP, Spooner AJ, Booth N, Penny RA, Gordon LG, Downer T-R, Yates P, Henderson R, Bradford N, Conway A et al. Qualitative insights of patients and carers under the care of nurse navigators. Collegian. 2019; 26(1):110117.

18. Braun V, Clarke V. Using thematic analysis in psychology. Qual. Res. 2006; 3(2):77-101.

19. Van Dyk J, Siedlecki S, Fitzpatrick J. Frontline nurse managers' confidence and self-efficacy. J. Nurs. Manag. 2016; 24(4):533-539.

20. Duffield C, Kearin M, Johnston J, Leonard J. The impact of hospital structure and restructuring on the nursing workforce. Aust J Adv Nurs. 2007; 24(4):4246.

21. Hawes S: "take the lead" strengthening the Nursing/Midwifery Unit Manager role across NSW, Report Phase One. In. Sydney: NSW Health; 2009.

22. McCallin AM, Frankson C. The role of the charge nurse manager: a descriptive exploratory study. J Nurs Manag. 2010; 18(3):319-325.

23. Casey M, McNamara M, Fealy G, Geraghty R. Nurses' and midwives' clinical leadership development needs: A mixed methods study. J. Adv. Nurs. 2011; 67(7):1502-1513.

24. Pillay R. The Skills Gap in Nursing Management in the South African Public Health Sector. Public Health Nurs. 2011; 28(2):176-185.

25. Duffield $C$, Roche M, Dimitrelis S, Frew B. Leadership skills for nursing unit managers to decrease intention to leave. Nurs: Res and Rev. 2015; 5.

26. Riddell S. "Why do nurses believe they are management material"? Nurs Times. 2011; 107(46):11.

27. Newman S, Lawler J. Managing health care under New Public Management: A Sisyphean challenge for nursing. J. Sociol. 2009; 45(4):419-432.

28. Baumgartner RJ: Generic management: a basis for implementing sustainable business management. In: 4th International Conference on Management of Technology. Vienna, Austria.; 2005.

29. Duffield CM, Roche MA, Dimitrelis S, Homer C, Buchan J. Instability in patient and nurse characteristics, unit complexity and patient and system outcomes. J Adv Nurs. 2015; 71(6):1288-1298.

30. El Haddad M, Wilkinson G, Thompson L, Faithfull-Byrne A, Moss C. Perceptions of the impact of introducing administrative support for nurse unit managers: A qualitative evaluation. J. Nurs. Manag. 2019; 27(8):17001711.

31. Ciezar-Andersen S, King-Shier K. Detriments of a Self-Sacrificing Nursing Culture on Recruitment and Retention: A Qualitative Descriptive Study. Can. J. Nurs Res. 2020:0844562120908747.

32. Heinen MM, van Achterberg T, Schwendimann R, Zander B, Matthews A, Kózka M, Ensio A, Sjetne IS, Moreno Casbas T, Ball J et al. Nurses' intention to leave their profession: a cross sectional observational study in 10 European countries. Int J Nurs Stud. 2013; 50(2):174-184.

33. Rhéaume A, Clément L, Lebel N. Understanding intention to leave amongst new graduate Canadian nurses: a repeated cross sectional survey. Int I Nurs Stud. 2011; 48(4):490-500.

34. Fishbein M, Ajzen I: Predicting and Changing Behavior: The Reasoned Action Approach. In., 1st ed. edn. United Kingdom: Psychology Press; 2009

35. Crossley CD, Bennett RJ, Jex SM, Burnfield JL. Development of a global measure of job embeddedness and integration into a traditional model of voluntary turnover. J Appl Psychol. 2007; 92(4):1031-1042.

36. Lucas MD, Atwood JR, Hagaman R. Replication and validation of anticipated turnover model for urban registered nurses. Nurs Res. 1993; 42(1):29-35.

37. Burns PB, Rohrich RJ, Chung KC. The Levels of Evidence and their role in Evidence-Based Medicine. Plast. Reconstr. Surg. 2011; 128(1):305-310.

\section{Publisher's Note}

Springer Nature remains neutral with regard to jurisdictional claims in published maps and institutional affiliations.

\section{Ready to submit your research? Choose BMC and benefit from:}

- fast, convenient online submission

- thorough peer review by experienced researchers in your field

- rapid publication on acceptance

- support for research data, including large and complex data types

- gold Open Access which fosters wider collaboration and increased citations

- maximum visibility for your research: over $100 \mathrm{M}$ website views per year

At BMC, research is always in progress.

Learn more biomedcentral.com/submissions 